\title{
Comparison of the personality characteristics and coping strategies between the patients with irritable bowel syndrome and normal individuals
}

\author{
Khaledian $\mathbf{H}^{1}$, Parhizkar $\mathbf{B}^{2}$, Shikhesmaeili $\mathbf{F}^{2}$, Moradi $\mathbf{M}^{3}$ \\ 1. MSc of General Psychology, Education Organization, Sanandaj, Iran. ORCID ID: 0000-0002-2918-3025 \\ 2. Assistant Professor of Gastroenterology and Hepatology, Liver and Digestive Research Center, Research Institute for \\ Health Development, Kurdistan University of Medical Sciences, Sanandaj, Iran. \\ 3. MSc of Biostatistics, Vice Chancellor for Research and Technology, Kurdistan University of Medical Sciences, Sanandaj, \\ Iran (Corresponding Auther), Tel: +98-87336646432, Email: masoud.722@gmail.com, ORCID ID: 0000-0002-7813-9518
}

\begin{abstract}
Background and Aim: Personality and stress are associated with irritable bowel disease. The aim of this study was to compare personality characteristics and coping strategies between the patients with irritable bowel syndrome and normal individuals.

Material and Method: In this cross sectional study we selected 200 people (100 irritable bowel syndrome patients and 100 normal individuals) on the basis of convenient method. We used two questionnaires including the NEO- Five Factor personality Inventory and LazarusFolkman coping Questionnaire for data collection. Data were analyzed by t-test and Mannwhitney U Test.

Results: The results showed that the mean scores of neuroticism factor in the patients with irritable bowel syndrome were higher than those in the normal individuals. While the mean scores of extraversion and conscientiousness factor in the normal subjects was higher than those in the patients with irritable bowel syndrome. There were no significant differences between the two groups in openness and agreeableness. Data showed that normal individuals compared to the patients with irritable bowel syndrome, used more problem- oriented coping styles. There were no significant differences between the two groups in regard to the escapeavoidance variable.
\end{abstract}

Conclusion: The results showed that IBS was affected by personality characteristics and coping strategies. Study of these factors can have many applications in the fields of research, etiology and treatment of this disease.

Keywords: Personality characteristics, Coping strategies, Irritable bowel syndrome

Received: Fev2, 2019

Accepted: May19, 2019

How to cite the article: Khaledian H, Parhizkar B, Shikhesmaeili F, Moradi M. Comparison of the personality characteristics and coping strategies between the patients with irritable bowel syndrome and normal individuals. SJKU 2019;24(3):85-95. 


\section{مقايسه ويزگى هاى شخصيتى و راهبر دهاى مقابله ای در بيمار ان مبتلا به نشانكان روده تحريك يذير و افراد بهنجار}

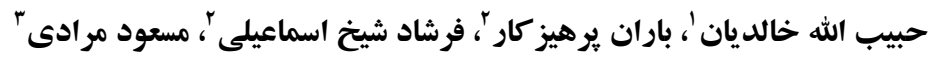

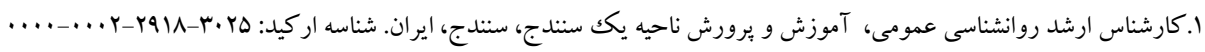

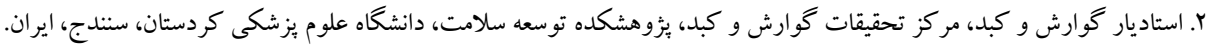

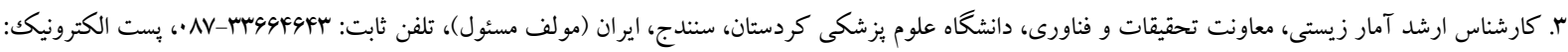

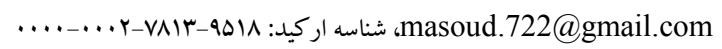

جكيده

زمينه و هدف: ويزگى هاى شخصيتى و استرس با بيمارى روده تحريك يذير رابطه دارد. ئزهش حاضر با هدف مقايسه ويزگى

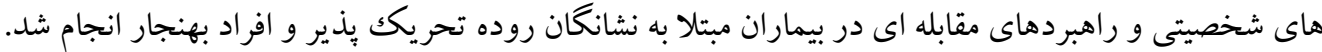

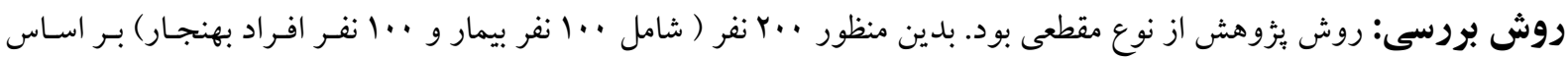

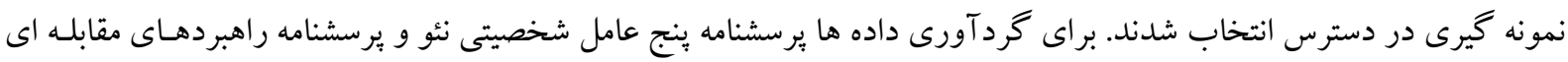

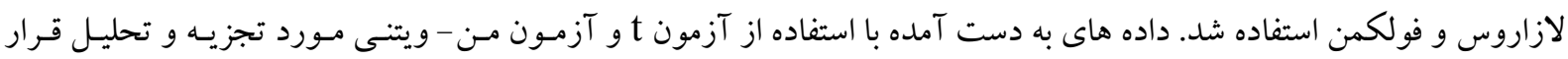

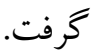

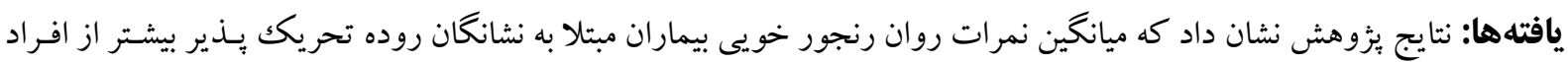

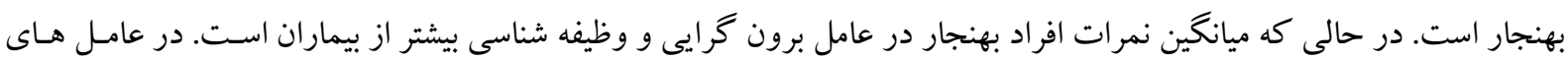

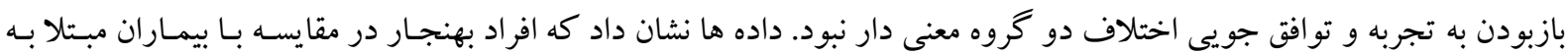

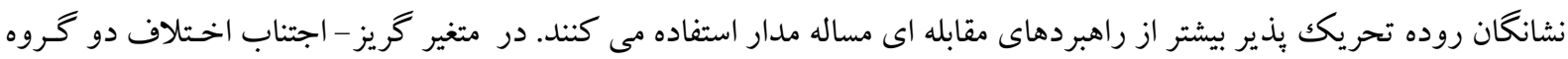
معنى دار نبود. نتيجه كيرى: بر اساس نتايج اين يزوهش، ويز گى هاى شخصيتى و راهبردهاى مقابله ای در بيماران داراى نشانگان روده تحريكك يذير تاثير و افراد سالم تفاوت دارند و بررسى اين عوامل مى تو اند كاربرد فراوانى در زمينه هاى بزوهشى، سبب شناسى و درمان اين بيمارى داشته باشد. كليد وازه ها: ويز گى هاى شخصيتى، راهبردهاى مقابله ای، نشانگان روده تحريكك بذير

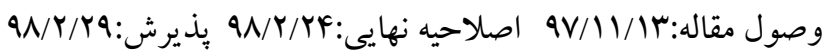




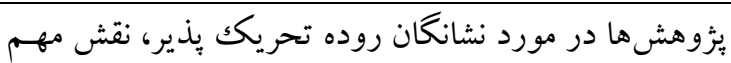
عوامل روانشناختى را در توضيح نشانههـاى بيمـارى و راه-

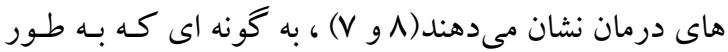

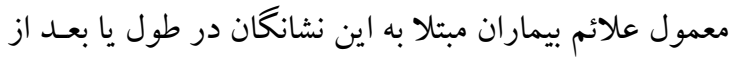
دورهاى از فشـار روانسى ظـاهر مسىشـود. در ايسن بيمـارى

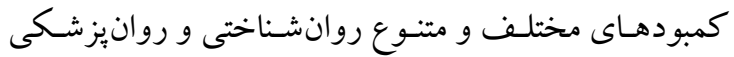
كزارش شده است. اضطراب و افسردگى در بيمـاران IBS

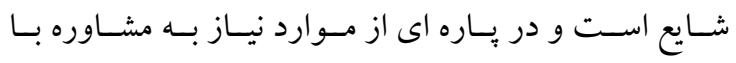

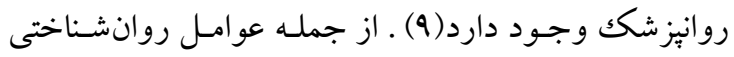
دخيل در سبب شناسى و تشديد علائم بيماران مبـتلا بـه ايـن

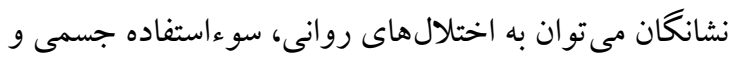

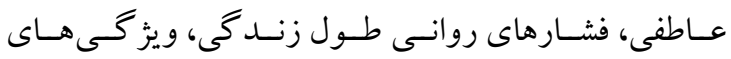

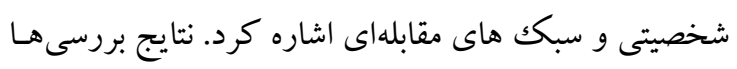
نشان مى دهند كه در هـ درصد بيماران، عوامل روانى مقــدم

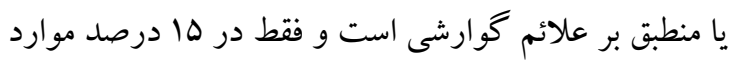

علائم گوارشى قبل از عوامل روانى ديده مى بـود (r).

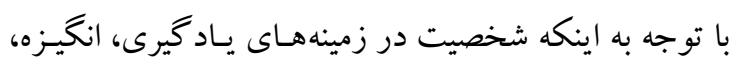

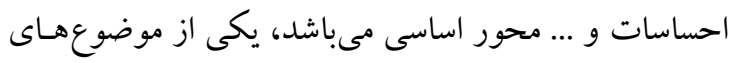

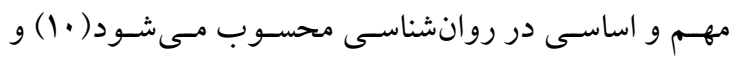

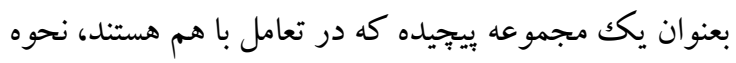

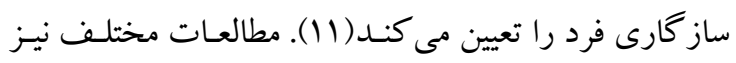

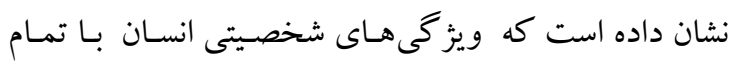

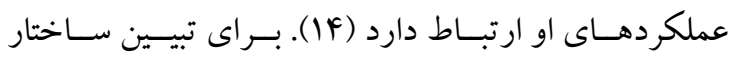

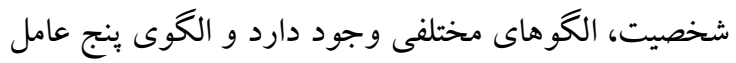

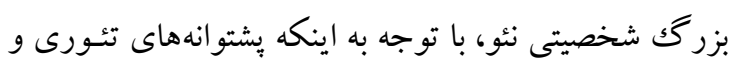

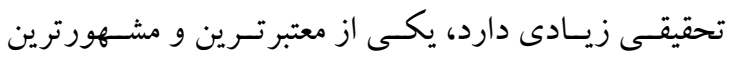

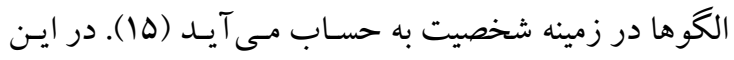

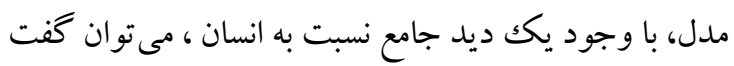
تقريبا تمامى صفات مورد اشاره در ميان عامه مردم و نظريـه

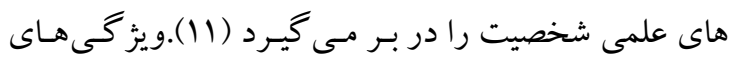

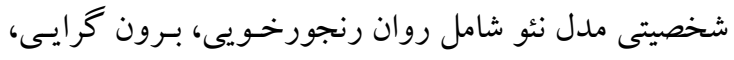

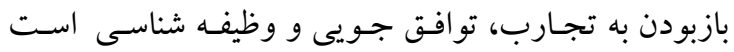

امروزه مطالعه اختـلالهـايى كـه داراى ريشـه روانشـناختى بوده و يا جنبه روانشناختى قوى دارند، بيش از بـيش مـورد

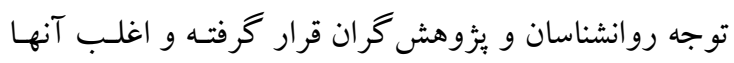
معتقدند كه برخى از عوامل روانشـناختى مسىتو انـد فرد را

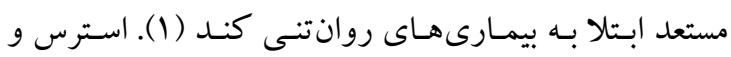

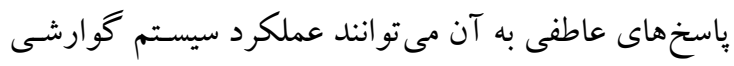
را تحت تاثير قرار دهند. نقش انواع عواطف و هيجانـات بر

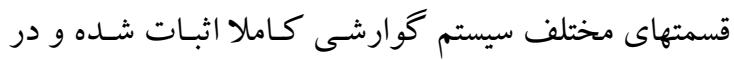

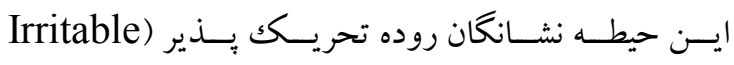

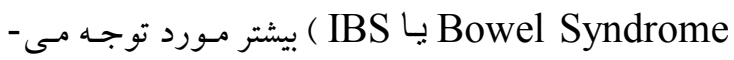

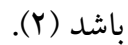
شـامل برخسى از اخـتلالات مربـوط بـه عملكـرد روده

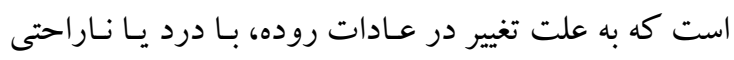

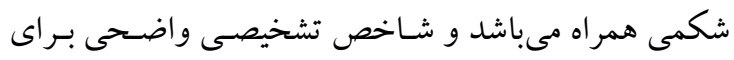

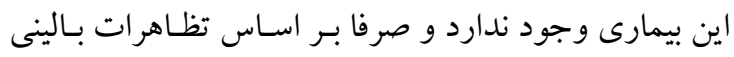
تشخيص داده مى شود (r) و اين بيمارى يكى از شايع ترين

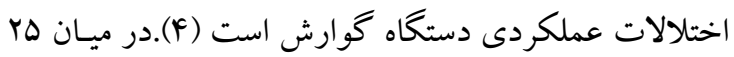
اختلال كاركردى كوارشى، IBS شايعترين، يرهزينه تـرين و ناتوان كنندهترين آنهاست (ه).در بررسى هاى انجام شـده،

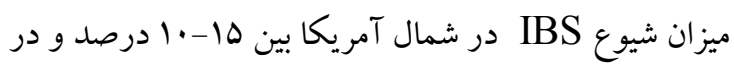
اروبا ه/11 درصد گزارش شـده اسـت. بـر اسـاس مطالعـات

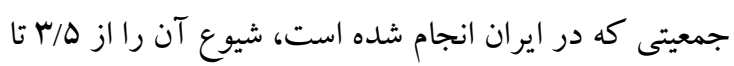

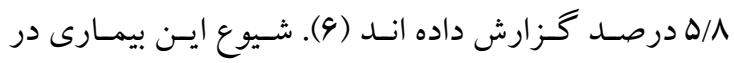
كشورهاى غربى بيشتر از كشـورهاى شـرقى است، مـثلا در

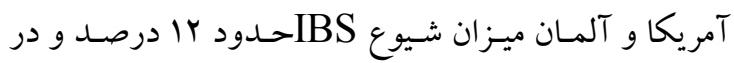

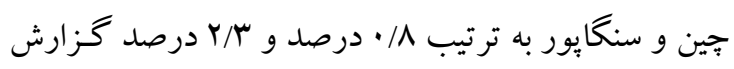

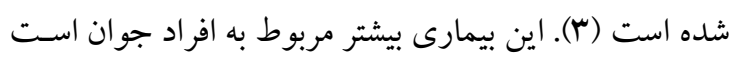

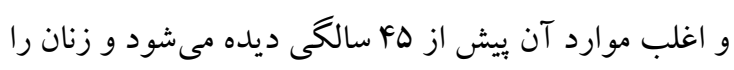

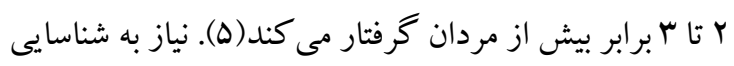

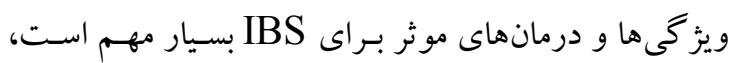

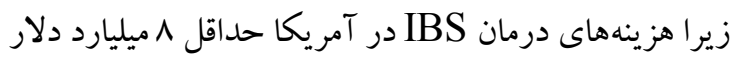
در سال مىباشد (9). (9) - (9) 
بيمارستانها و مطـبـهـاى خصوصى شـهر سـنتدج مراجعـه

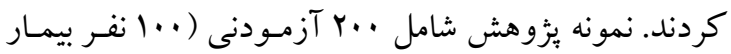
مبتلا به نشانگان روده تحريك يذير و ..انفر افراد بهنجـار همـراه آنـان) بـود كـهـ در فاصـله زمـانى انجـام يـرّوهش بــه بيمارسـتان توحيـد سـنندج و دو مطـب خصوصسى در شـهر

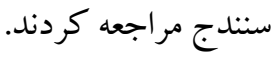

روش جمع آورى داده ها

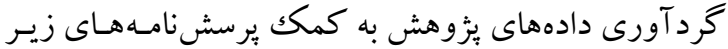
انجام شد: يرسش نامه يـنج عـاملى نئسو - تجديــ نظـر شـده (NEO-FFI-R) شخصيت نئو (NEO-PI-R ) است كه براى سـنجش يـنج عامل شخصيت افراد بزر گسال تهيه شده است. اين برسش نامه شامل •9 ماده است كه در سال 9199 ابـر اسـاس تحليـل عاملى نمرات فرم بلند (NEO-PI-R ) كـه در سـال 1919 اجرا شده بود، بهدست آمـده اسـت. فرم كوتـاه .9 مـادهاى

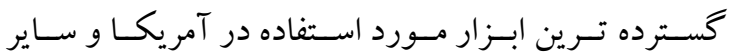
كشورهاى جهان مىباشد. در هر سوال، آزمودنى نمره صـفر تا جهار را احراز مى كند(IV) ـ هـر يـك از سـو الهــا نشـاندهنده يكى از يـنج عامـل بـزرك شخصـيت مـك كرى و

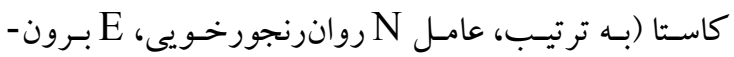

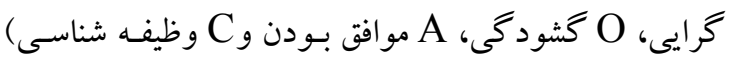
است. هر يكك از عوامل، با سـوال مقيـاس را يوشـش مسى دهند. دامنه نمرات براى هر مقياس، صفر تا FA است كـه بـا

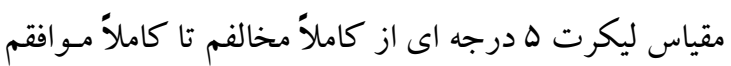
تنظيم يافته است. همسانى درونى اين برسشنامه از 91/ • تا A9/ • و باز آزمايى

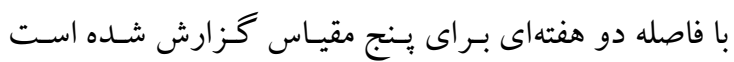

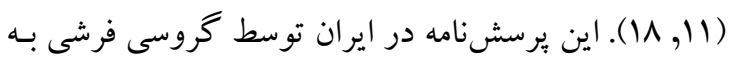
زبان فارسى ترجمه و برروى دانشـجويان ايرانسى هنجاريـابى شده اسـت. ضـر ايب اعتبـار بدسـت آمـده از مطالعـه وى بـهـ روش آلفاى كرونباخ براى عوامـل اصـلى بـه ترتيـب 9\$1/•،

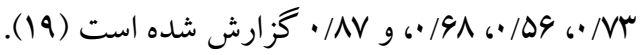
برسشنامه راهبردهـاى مقابلـهاى لازاروس و فولكمن: ايـن يرسشنامـه كـه توسط لازاروس و فـولكمن ( هA9 (1) تهيـه
علاوه بر ويز گیىهاى شخصيتى، توانـايى بيمـار در مقابله بـاـ استرسهاى زندگى روزمـره نيـز در بيشــيرى از ييامـدهاى منفى اختلال نشانگان روده تحريك يذير موثر است. مقابله در واقع به تلاشهايى كفتـه مسىشـود كـه فـرد بـا توجـه بـــ شناخت محيط و رفتارى كه انجام مسدهــ، بـراى برطرف كردن شر ايط استرس زا انجـام مسىدهـ (fأ و سا). از نظر لازاروس و فـولكمن شـيوههــاى مقابلـه بــا فشـار روانسى، فر آيندى است كه خواستهها و الزامات درونسى و بيرونى را مشخص مى كند و براى بِاسخ دادن بـه محركى كـه تهديــ كننده است، بر اساس تجربـه، تغييـر مسى كنــ (ها). دو نـوع راهبرد مقابله اى در برابـر فشـار روانسى وجـود دارد: راهبـرد مقابلهاى مسـئله مــدار و راهبـرد مقابلـهاى هيجـان مــار ـ. در راهبرد مقابلهاى مسـئله مــار، فـرد بـا جمـع آورى اطلاعـات درخصوص حادثه استرس زا، سعى مسى كنــ نقشـهاى بـراى حل مساله بكار ببرد. درواقع در ايسن راهبـرد، فـرد بـر مسـاله اصلى تمر كز مى كنــد و بـا اقـدامات مناسـب سـعى مهى كنـــ مسـاله را حـل كنـــ و شـرايط اسـترسزا را از بـين بيـرد. در راهبرد مقابلهاى هيجان مدار، فرد بيشتر روى خودش تمركز مى كند و در واقع با تنظيم هيجان ناشى از عامـل اسـترس زا، تلاش مى كند احساسات و هيجاناتش را كم كند (19). بر اساس بررسى مطالعات صورت گر فته، تا كنون كمتـر بــ بررسى همزمان دو عامل ويز گیىهاى شخصيتى و راهبردهاى مقابلهاى در بيماران مبـتلا بـه نشـانكان روده تحريـك يـــير برداخته شده لذا يُوهش حاضر، به منظور بررسى مقايسهاى ويز گَى هـاى شخصسيتى و راهبردهـاى مقابلـهاى در بيمـاران مبتلا به نشانكان روده تحريـك يـذير و افراد بهنجـار انجـام نوع مطالعه و نمونه تيرى يثروهش حاضر يكك مطالعه مقطعى مسىباشـد. جامعـه مـورد مطالعه، شامل كليه بيماران مبتلا بـهـ نشـانكان روده تحريـك

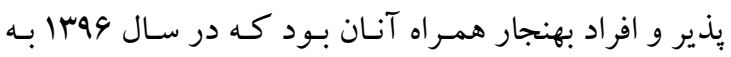




\section{روش آمارى}

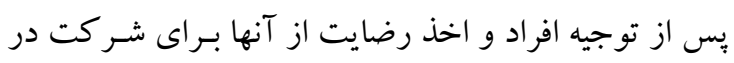

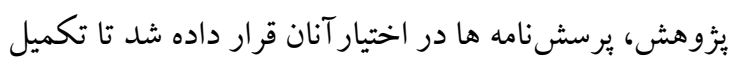

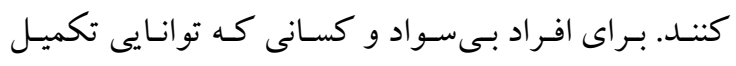

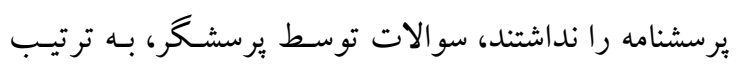

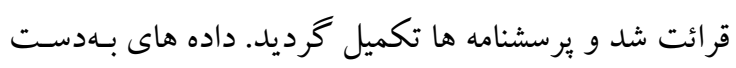

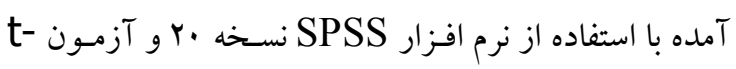

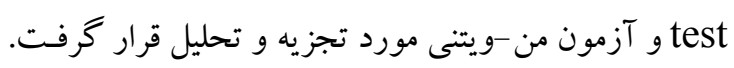

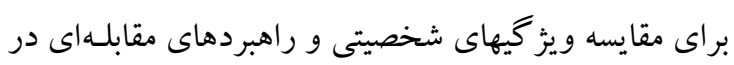

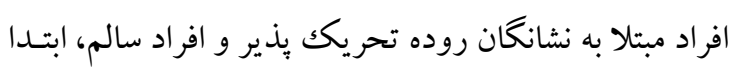

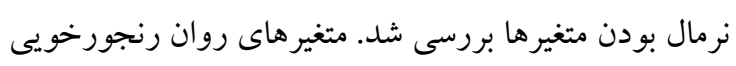

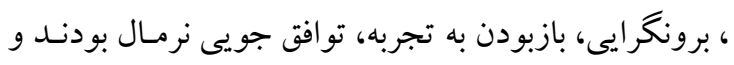

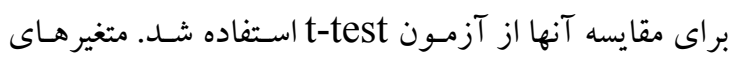
وظيفـه شناسى، جستجوى حمايست اجتمـاعى، مسـؤئيت

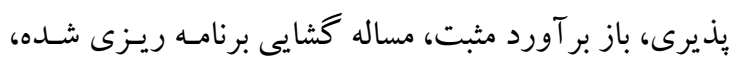

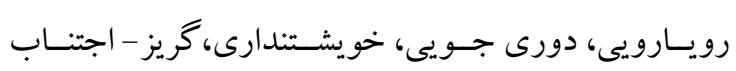

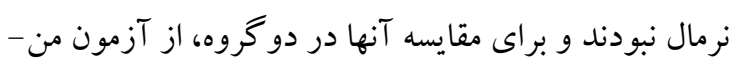

ويتنى استفاده شد.

يافته ها

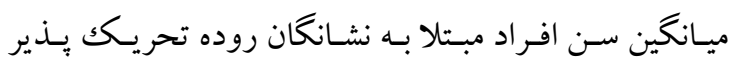

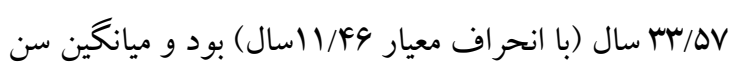

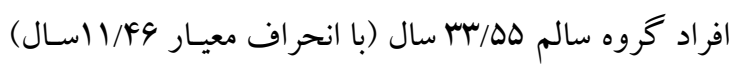
بود. نتايج نشان داد كـه مشخصات دمو گر افيكك دو گروره

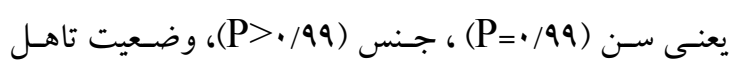

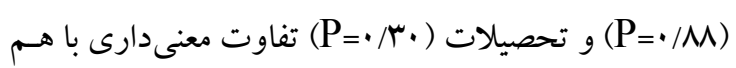

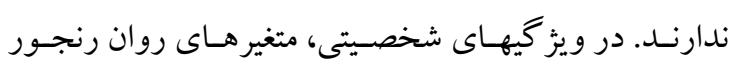
خويى و برون گر ايى در دو گروه اختلاف معنى دارى دارند

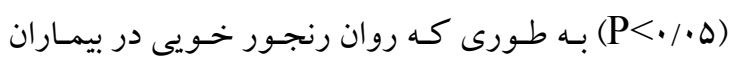

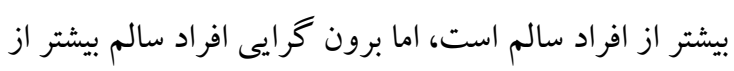

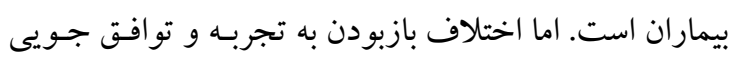

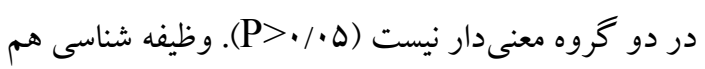

شده است، دامنه وسيعى از افكار و اعمالى كه افراد، هنگَام

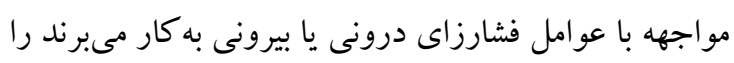

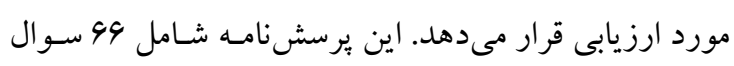

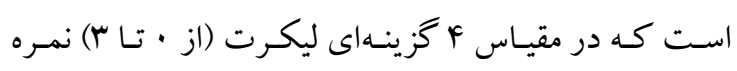

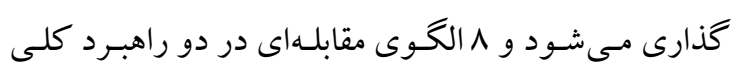

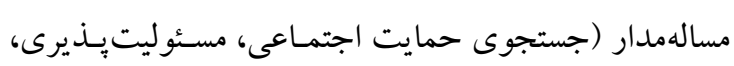

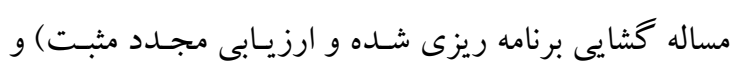

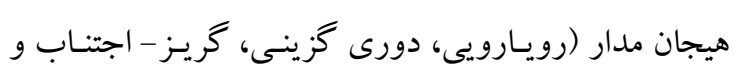

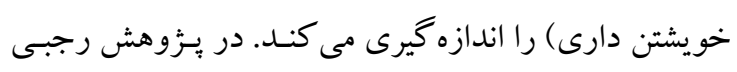
دماوندى و همكارانش ضريب آلفاى كرونباخ مقابله هيجان

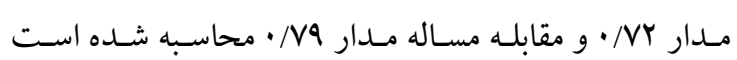

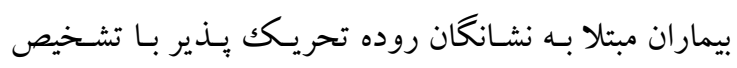

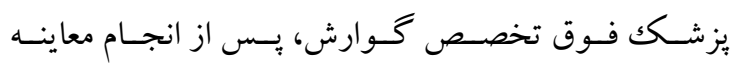

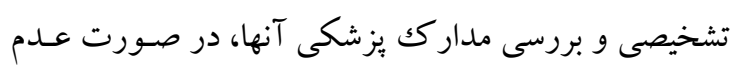

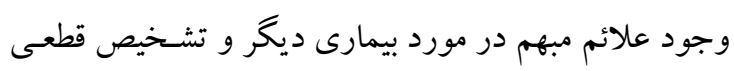

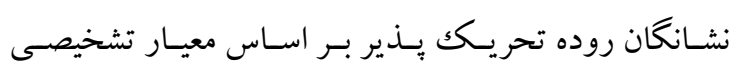
ROM III

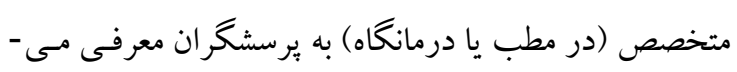

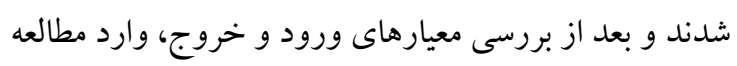

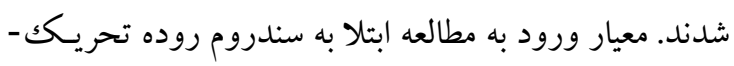

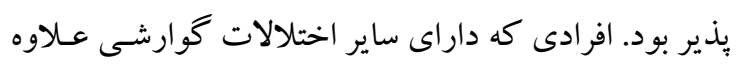

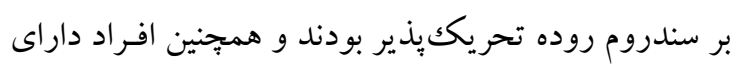

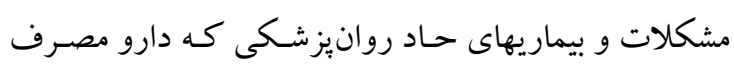

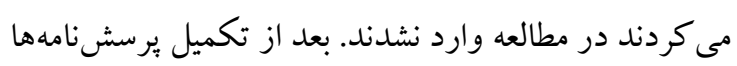

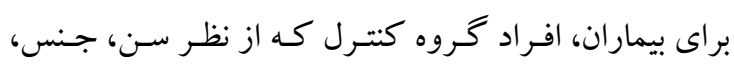

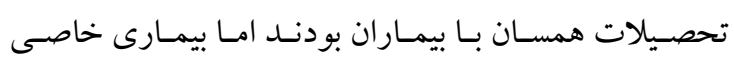
نداشتند انتخاب و برسشنامه ها براى آنها نيز تكميل كرديد. كروه كنترل از افر اد نزديكك ، همر اهـان و خـانو اده بيمـاران

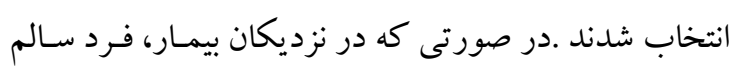

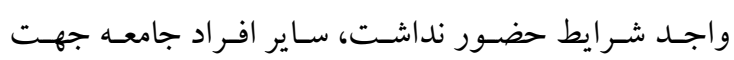
شر كت در مطالعه انتخاب شدند. 


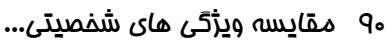

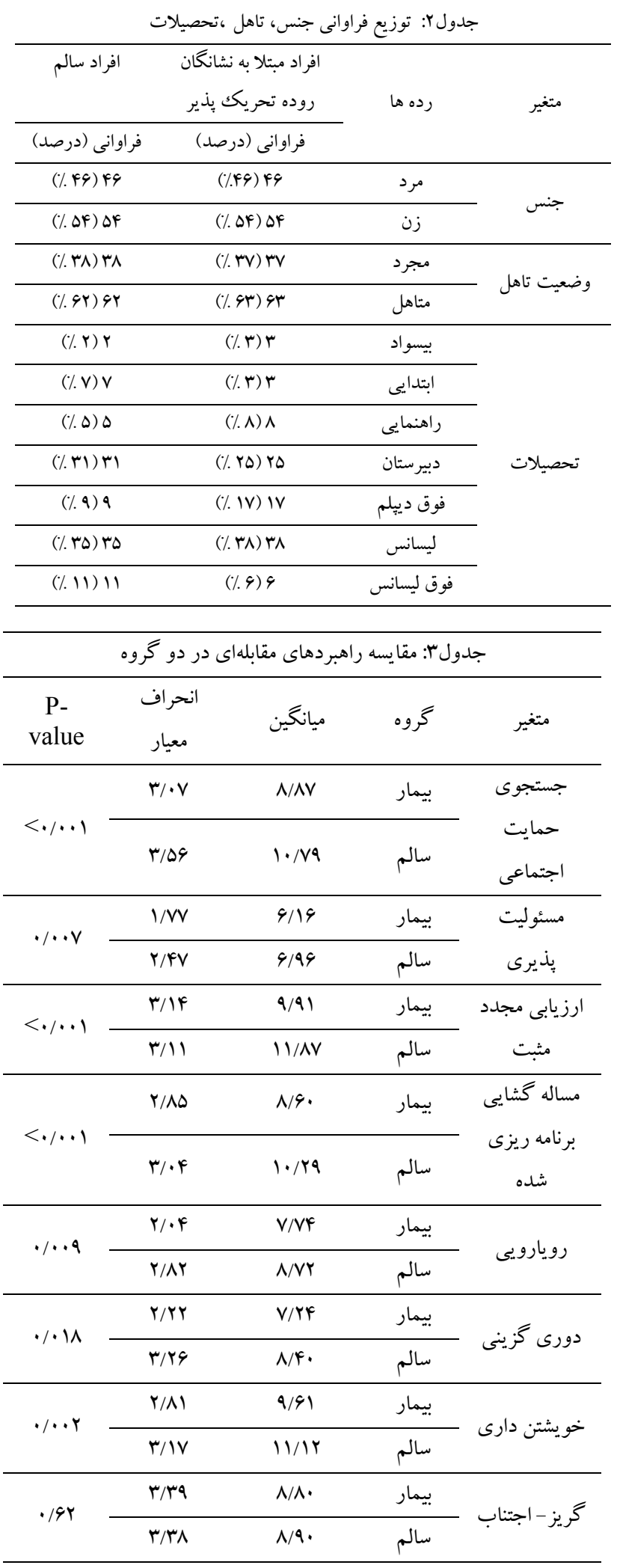

در افراد سالم بالاتر از بيماران است و اين اختلاف معنى دار

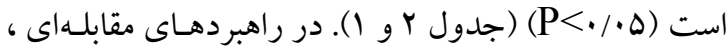

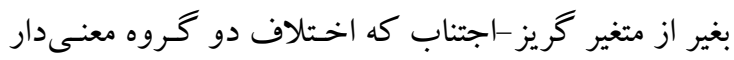
نشده است (ه.. •P>) براى ساير متغير ها، دو گروه اختلاف

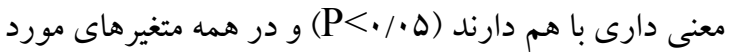
افراد سالم نمره بالاترى كسب كرده اند (جدولى). مشخصـات دمو گر افيـك افـر اد مبـتلا بـه نشـانكان رودهه تحريك بذير بهصورت زير است.

\begin{tabular}{|c|c|c|c|c|}
\hline P-value & انحر اف & ميانگين & كروه & متغير \\
\hline \multirow[b]{2}{*}{$<\cdot / \cdot \cdot 1$} & $\Delta / F^{\prime}$ & $r F / \cdot \Lambda$ & بيمار & \multirow{2}{*}{ رونجورخ ريد } \\
\hline & $G / Y V$ & IN/AG & سالم & \\
\hline \multirow{2}{*}{ r } & $\Delta / \Lambda F$ & $r N / 99$ & بيمار & \multirow{2}{*}{ برون گرايى } \\
\hline & $0 / 90$ & $r \cdot / \Delta \Delta$ & سالم & \\
\hline \multirow{2}{*}{$\cdot / \mathrm{M}$} & r/N & YF/GA & بيمار & بازبودن به \\
\hline & $F / r r$ & $r \Delta / \Lambda \Lambda$ & سالم & تجربه \\
\hline \multirow{2}{*}{$\cdot / 4 q$} & $F / \Lambda \mid$ & $\mu \cdot / \mu F$ & بيمار & تو افق \\
\hline & $\Delta / \mu$ & $r \cdot \mu$ & سالم & جويى \\
\hline \multirow{2}{*}{$\cdot / \cdot r$} & $0 / 90$ & $M / F \Delta$ & بيمار & وظيفه \\
\hline & $9 / \pi Y$ & 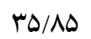 & سالم & شناسي \\
\hline
\end{tabular}


برخوردار هستند (ז, سY-Y|Y). بر اساس مدل نئو، در كسانى

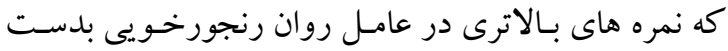

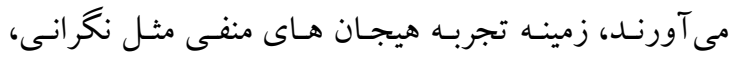
احساس گناه، كم رويى، خشم و ناميدى بيشتر وجـود دارد

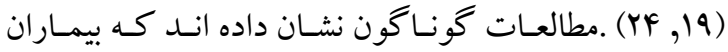
د در طول زندگى شان، فشار روانى را به ميزان بيشترى نسبت به افراد سالم تجربه مى كنند و در اغلب موارد، شروع

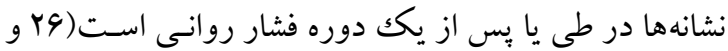

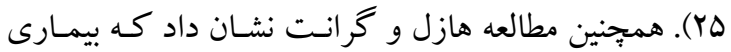

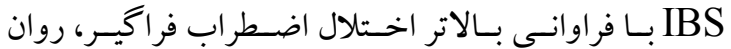
رنجورخويى و اختلال جسمانى شكل در ارتباط است(YV).

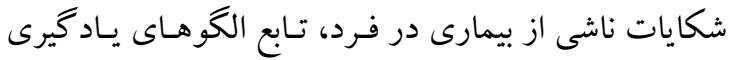

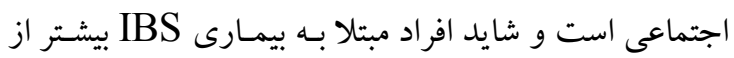

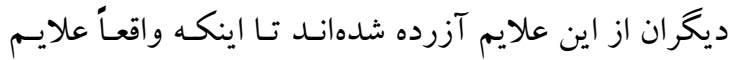
بيشترى داشته باشند (YI). فرنام و همكاران نيـز بـهـ كاستى إنى

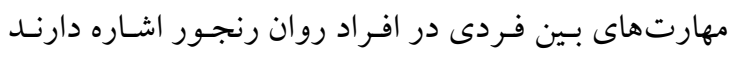

افراد مبتلا به IBS، نمره برون گرايى كمترى نسبت به افراد

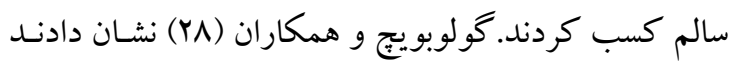

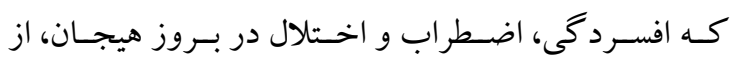

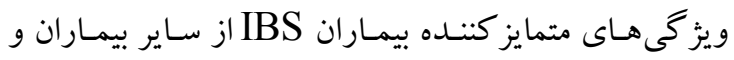

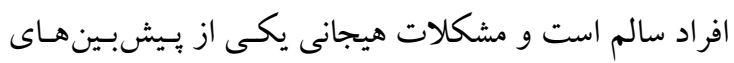
اصلى اختلال در روابط بين فردى است. باقريان سرارودى و همكاران معتقدند كه سبكك زندگى وابسته به سلامت مختل

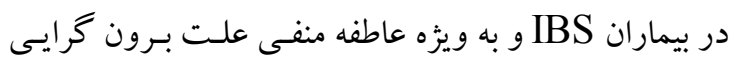
كمتر در اين افراد است (IاY). از اين رو مى تـوان بخشى از

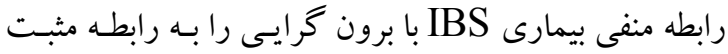

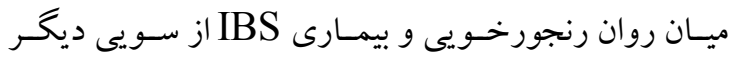

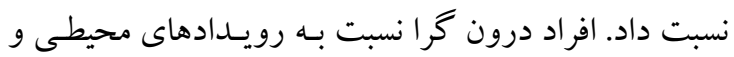
نسبت به اتفاقات بدنى خود، حسـاس ترنـد و ايـن بـه شكل گيرى رفتارهايى در فرد منجر مى گردد كه دريافت تقويـت و حمايت اجتماعى كمتر و اجتناب فرد از جامعه را به دنبال

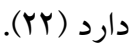


كيرد از سلامت روانى كمتـرى برخوردار اسـت و آسيب

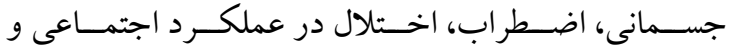
افسردگى بيشترى خو اهد داشت (Yr). بهادرى خسروشاهى و خانجانى نيز به اين نكته اشـاره مسى كنند كه افرادى كـه در موقعيـتهـاى اسـترسزا از راهبرد مساله مدار استفاده مى كنتـد؛ در واقع فعاليـتهـاى مـنظم و دسته بندى شده را براى بازسازى دوباره مساله از نظر ذهنى مدى في

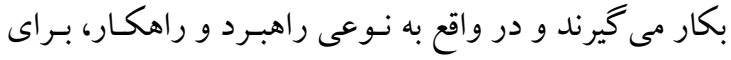

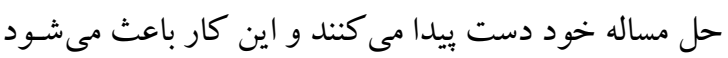
فشار روانى كم شود و سلامت روان افزايش بيدا كند(19). در حاليكه بسيارى از مردم در انتخاب راهبردهـاى مقابلهاى

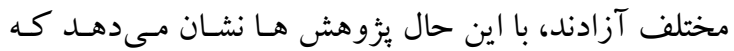

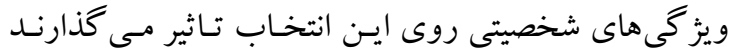

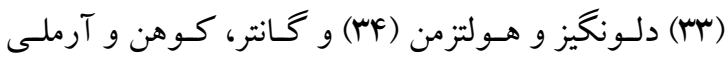

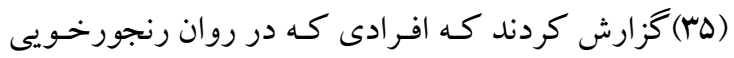
نمرات بالايى مى گيرند، در برابر استرس راهبرد هاى مقابله اي ضعيفى دارند و همين باعث تشـــيد استرس مسى شـود. بنابراين به نظر مىرسد صفات شخصيت، زمينه ساز عواملى

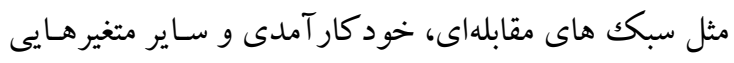
است كه به عنوان متغيرهاى واسطهاى در تجربـه استرس و و هيجانات منفى محسوب مسىشوند. از طـرف ديخـر، بـايين بودن نمرات ويز گى هاى مثبت شخصيت و بالا بـودن نمـره

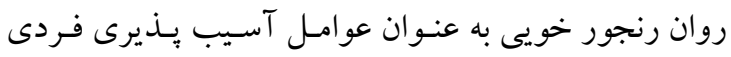

محسوب مى شود ( ) (11).

\section{نتيجه كيرى}

در مجموع يافته هاى اين يُزوهش نشان دهنده آن است كـه

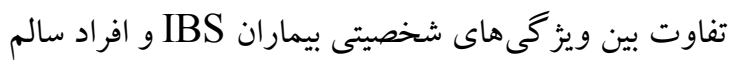
مى تواند ريشه در ساختار كلى جسمانى و روان شناختى اين

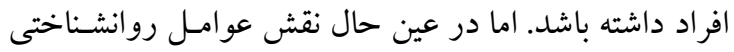

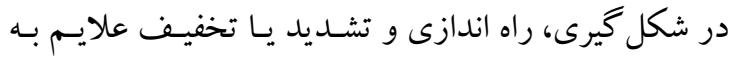

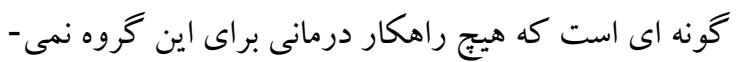

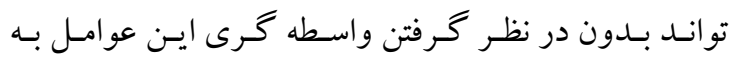
موفقيت دست يابد. انجام يُزوهش هايى كامل تر و همجنين

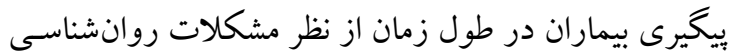

همجنين بيماران دجار IBS، در وظيفهـ شناسى نمـره پِياين ترى از افراد سالم كسب كردند در توجيه تفاوت موجود در بين دو گروه بيمار و سالم در اين عامل، مىتوان كفت كـه وظيفه شناسى با ويزگى هايى در فرد مشخص مى شود كـه از

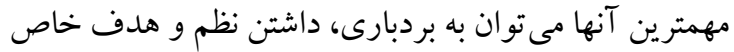
در زندگى اشاره كرد و نمره بالاى وظيفه شناسى نشان مى دهد كه فرد مسئوليت بذيرى بالايى دارد (Yq).

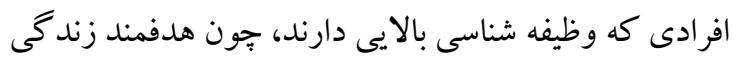

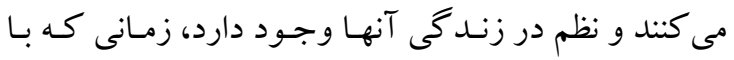
مشكل مواجه مىشوند بصورت هيجانى عكس العمـل نشـان نمىدهند وبيشتر از روشها و راهبردهاى مساله مدار استفاده

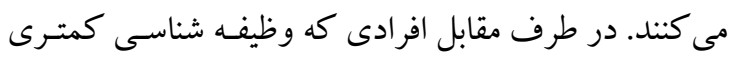

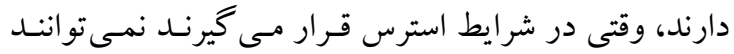

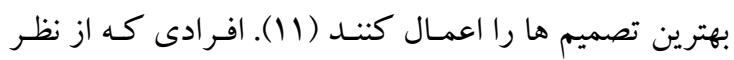
وجدانى بودن نمره بالايى به دست مى آورند، افرادى هستند كه كنترل خويشتن زيادى دارند و فعالانه وظايف خهود را

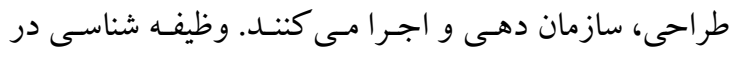

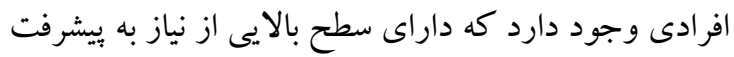

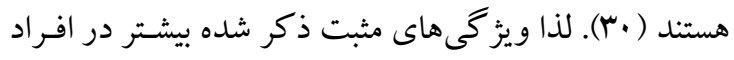

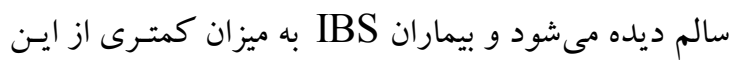
ويز گى ها بهره مندند. با توجه به نتايج بزوهش حاضر، افراد عاد عـادى بـيش از افراد داراى بيمـارى IBS از راهبردهــاى مقابلـهاى مسـاله مــدار استفاده مى كنند. بزوهشهاى ديخرى نيز اين يافتـه را تاييـد

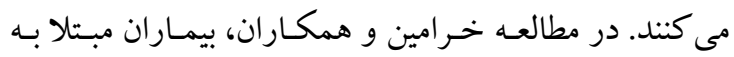
زخـم معـده، دوازدهـه و IBS در مقايسـه بـا افر اد سـالم از

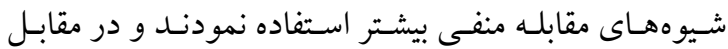
استفاده از شيوههاى مقابلهاى مثبت يا كار آمد در افراد سالم بيشتر مورد استفاده قرار گرفته بود (آ). غضنفرى و قدم يور بــه ايـن نكتـه اشـاره مسى كنتـد كـه بـين سلامت روانى و راهبردهاى مقابلهاى رابطه معنىدارى وجود دارد. به اين ترتيب كه هرجه فرد راهبرد مقابله مساله مدار را

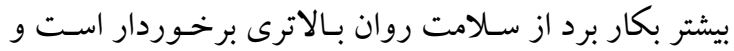
بالعكس هر جه فرد راهبرد مقابله هيجان مدار را بيشتر بكار 


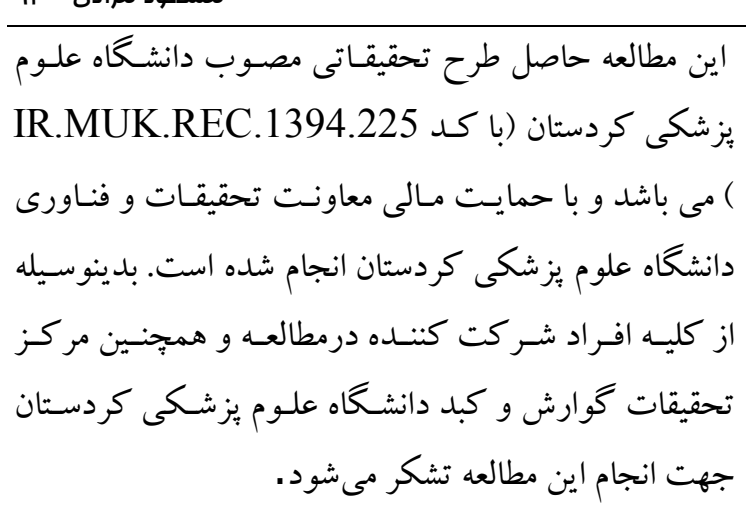

\section{References}

1. Sadock BJ, Sadock VA, Ruiz P. Kaplan and Sadock's Synopsis of Psychiatry, Behavioral sciences/clinical psychiatry.11th ed. Tranlated by Farzin Rezaei. Tehran: Arjmand; 2015.

2. Mirzaeian B, Mansoori M. Comparison of attachment styles and coping strategies in irritable bowel syndrome and healthy female students. J Gorgan Univ Med Sci 2013;15:54-9. [In Persian]

3. Taheri M, Hasani J, Hosinian S. The comparison of the personality characteristics of the irritable bowel syndrome patients, patients with other gastrointestinal diseases and normal individuals. J Clinical Psychology Sci 2012;4:53-62.

4. Solati Dehkordy S, Kalantary P, Adibi M, Afshar H. Effect of relaxation with drug therapy on the psychological symptoms in patients with irritable bowel syndrome-diarrhea dominant (IBS-D). J Shahrekord Univ Med Sci 2009;11:1-8. [In Persian]

5. Tanhaee Z, Fathi-Ashtiani A, Amini M, Vahedi H, Shaghaghi F. Validation of a revised version of the short-form mc-gill pain questionnaire (SF-MPQ-2) for IBS Patients. Govaresh 2012;17:91-7.

6. Moghtadaei K, Kafi M, Afshar H, Ariapouran S, Daghaghzadeh H, Pourkazem T. Effectiveness of mindfulness-based cognitivegroup therapy on somaticsymptoms inwomen withirritable bowel syndrome. J Res Behav Sci 2013;10:698-708.

7. Drossman DA. Do psychosocial factors define symptom severity and patient status in irritable bowel syndrome?. Am J Med Sci 1999;107:41-50.

8. Jones MP, Wessinger S, Crowell MD. Coping strategies and interpersonal support in patients with irritable bowel syndrome and inflammatory bowel disease. Clin Gastroenterol Hepatol 2006;4:474-81.

9. Afshar H, Baharizadeh M, Daghaghzadeh H, Masaeli N, Merasy MR, Abidi P. The efficacy of fluvoxamine on irritable bowel syndrome severity and patients quality of life. $\mathrm{J}$ Res Behav Sci 2011;9:197-205.

10. Golparvar M, Barazandeh A, Javadian Z. The relationship between big five personality factors and belief in an unjust and a just world, beliefs of justice compensation. CPAP 2014;2:61-74. [In Persian]

11. McCrae RR, Costa Jr PT. A contemplated revision of the NEO five-factor inventory. Pers Indiv Differ 2004;36:587-96.

12. Rajabi Damavandi G, Poushaneh K, Ghobari Bonab B. Relationship between personality traits and coping strategies in parents with children with autism spectrum disorders. Except Child 2009;9:133-44.

13. Gandom Kar P, Naderi F, Savari K. The effectiveness of coping strategies on flexibility of action and health of female students. TBCP 2013;8:57-66. [In Persian]

14. Hatamloo Sadabadi M, Babapour Kheirodin J. Comparison of quality of life and coping strategies in diabetic and non diabetic people. JSSU 2013;20:581-92. [In Persian] 
عاو هقايسم ويرَّى هاى شفميتى...

15. Bahadori Khosroshahi J, Hashemi Nosrat Abadi T. The relationships of attachment styles, coping strategies and mental health to internet addiction. J Iran Psychol 2011;8:177-88. [In Persian]

16. Bahadori Khosroshahi J, Khanjani Z. Relationship of coping strategies and self-efficacy with substance abuse tendency among students. Knowledge \& Research in Applied Psychology 2013;14:80-90. [In Persian]

17. Rajabi S, Narimani M. Effectiveness of Alpha/Theta neurofeedback on the big-five personality in individuals with dependent to morphine. Research in Clinical Psychology and Counselings 2015;4:5-20.

18. Anisi J, Majdiyan M, Joshanloo M, Ghoharikamel Z. Validity and reliability of NEO Five-Factor Inventory (NEO-FFI) on university students. IJBS 2011;5:351-5.

19. Garousi Farshi MT. New approach to personality assessment (Application of factor analysis in personality research). 1 ed nd. Tabriz: Jameeh Pajooh, 2001; 292.

20. Andrews E, Eaton S, Hollis K, Hopkins J, Ameen V, Hamm L, et al. Prevalence and demographics of irritable bowel syndrome: results from a large web based survey. Aliment Pharmacol Ther 2005;22:935-42.

21. Bagherian Sararoudi R, Afshar H, Adibi P, Daghaghzadeh H, Fallah J, Abotalebian F. Type D personality and quality of life in patients with irritable bowel syndrome. J Res Med Sci 2011;16:985-92.

22. Farnam A, Somi MH, Sarami F, Farhang S. Five personality dimensions in patients with irritable bowel syndrome. Neuropsychiatr Dis Treat 2008;4:959-62.

23. Ghasemi N. The comparison of personality traits in irritable bowel syndrome patients with normal matched group in Shiraz city. Knowledge Res Appli Psycho 2012;13:95-104.

24. Skinner TC, Hampson SE. Personal models of diabetes in relation to self-care, wellbeing, and glycemic control: a prospective study in adolescence. Diabetes Care 2001;24:82833.

25. Huerta I, Bonder A, Lopez L, Ocampo M, Schmulson M. Differences in the stress symptoms rating scale in Spanish between patients with irritable bowel syndrome (IBS) and healthy controls. Rev Gastroenterol Mex 2002;67:161-5.

26. Hunt MG, Moshier S, Milonova M. Brief cognitive-behavioral internet therapy for irritable bowel syndrome. Behav Res Ther 2009;47:797-802.

27. Hazel S, Grant M. Prevalence of IBS among university student and visceral anxiety. J Psychosom 2003;55:501-5.

28. Tosic-Golubovic S, Miljkovic S, Nagorni A, Lazarevic D, Nikolic G. Irritable bowel syndrome, anxiety, depression and personality characteristics. Psychiatr Danub 2010;22:41824.

29. Lane JD, McCaskill CC, Williams PG, Parekh PI, Feinglos MN, Surwit RS. Personality correlates of glycemic control in type 2 diabetes. Diabetes Care 2000;23:1321-5.

30. Mohammadzade Ebrahimi A, Rahimi Pordanjani T. The prediction of shift work tolerance by means of morning-type, rigidity sleeping habits and big five factors of personality. IOH 2013;10:82-91.

31. Kharamin S, Nilli H, Mohamadi A, Mobashery G. Comparison of coping skills in peptic ulcer, irritable bowel syndrome and normal people. Armaghane Danesh 2008;13:95-104. [In Persian]

32. Ghazanfari F, Ghadam Pour EA. The relationship between mental health and coping strategies in citizenship of Khoramabad city. Fundamentals of Mental Health Sci 2008;9:47[In Persian] 
90 (1)

33. Karimzade A, besharat M A. An investigation of the relationship between personality dimensions and stress coping styles. Procedia-Social and Behavioral Sciences 2011;30:797802.

34. DeLongis A, Holtzman S. Coping in context: the role of stress, social support, and personality in coping. J Pers 2005;73:1633-56.

35. Gunthert KC, Cohen LH, Armeli S. The role of neuroticism in daily stress and coping. J Pers Soc Psychol 1999;77:1087-100. 